\title{
Mortality Trends in Patients Hospitalized with the Initial Acute Myocardial Infarction in a Middle Eastern Country over 20 Years
}

\author{
Emad Ahmed, ${ }^{1,2}$ Jassim Al Suwaidi, ${ }^{1}$ Ayman El-Menyar, ${ }^{3,4,5}$ Hajar A. H. AlBinali, ${ }^{1}$ \\ Rajvir Singh, ${ }^{1}$ and A. A. Gehani ${ }^{1,3}$ \\ ${ }^{1}$ Department of Adult Cardiology and Cardiovascular Surgery, Heart Hospital, P.O. Box 3050, Doha, Qatar \\ ${ }^{2}$ Department of Cardiology, National Heart Institute, Cairo, Egypt \\ ${ }^{3}$ Department of Clinical Medicine, Weill Cornell Medical School, P.O. Box 24144, Doha, Qatar \\ ${ }^{4}$ Clinical Research, Trauma Section, Hamad Medical Corporation (HMC), P.O. Box 3050, Doha, Qatar \\ ${ }^{5}$ Internal Medicine, Cardiology Section, Ahmed Maher Teaching Hospital, Egypt
}

Correspondence should be addressed to A. A. Gehani; aa.gehani@gmail.com

Received 1 November 2013; Revised 19 February 2014; Accepted 4 April 2014; Published 28 April 2014

Academic Editor: Vladimír Džavík

Copyright (C) 2014 Emad Ahmed et al. This is an open access article distributed under the Creative Commons Attribution License, which permits unrestricted use, distribution, and reproduction in any medium, provided the original work is properly cited.

\begin{abstract}
We aimed to define the temporal trend in the initial Acute Myocardial Infarction (AMI) management and outcome during the last two decades in a Middle Eastern country. A total of 10,915 patients were admitted with initial AMI with mean age of $53 \pm 11.8$ years. Comparing the two decades (1991-2000) to (2001-2010), the use of antiplatelet drugs increased from $84 \%$ to $95 \%$, $\beta$-blockers increased from $38 \%$ to $56 \%$, and angiotensin converting enzyme inhibitors (ACEI) increased from $12 \%$ to $36 \%$ ( $P<0.001$ for all). The rates of PCI increased from $2.5 \%$ to $14.6 \%$ and thrombolytic therapy decreased from $71 \%$ to $65 \%(P<0.001$ for all). While the rate of hospitalization with Initial MI increased from $34 \%$ to $66 \%$, and the average length of hospital stay decreased from $6.4 \pm 3$ to $4.6 \pm 3$, all hospital outcomes parameters improved significantly including a 39\% reduction in in-hospital Mortality. Multivariate logistic regression analysis showed that higher utilization of antiplatelet drugs, $\beta$-blockers, and ACEI were the main contributors to better hospital outcomes. Over the study period, there was a significant increase in the hospitalization rate in patients presenting with initial AMI. Evidence-based medical therapies appear to be associated with a substantial improvement in outcome and inhospital mortality.
\end{abstract}

\section{Introduction}

Cardiovascular (CV) disease is a leading cause of morbidity and mortality worldwide. The epidemiology of coronary artery disease (CAD) is known to undergo changes over time. Some reflect changes in risk factors or management, while others are difficult to explain. What is certain is that changes in the rate and mortality from CAD have a major impact on the overall health care system [1].

Guidelines from major cardiac societies [2-4] strongly support the use of $\beta$-blockers (BB) and antiplatelet agents in patients who survive AMI. Several recent clinical trials [5] have also demonstrated the beneficial effects associated with the use of angiotensin converting enzyme inhibitors (ACEI) in patients with acute coronary syndrome (ACS), irrespective of the extent of left ventricular dysfunction.
The management of AMI has undergone impressive changes during the last 2 decades [2] and CAD mortality has also declined in many countries [6]. This decline in CAD mortality is partially related to a decrease in both the rate and the case fatality of this disease [7-9]. While reduced CAD M fatality is primarily related to the use of effective treatments [10-12], the decreased incident of CAD is largely explained by CV risk factors modification $[13,14]$.

In the present study, we analyzed the temporal trends in hospitalization rate, in-hospital mortality, and changes in the utilization of evidence-based therapies early in the course of initial AMI (both ST-elevation and non-ST-elevation). The association between such changes and the hospital outcomes were studied across two different time periods (1991-2000 versus 2001-2010). 


\section{Methods}

2.1. Study Setting. We conducted this cohort study in Qatar, which is a country in the Middle East. The population was around 600,000 (2001 Census) and 1.6 million (2010 Census). This study was based at the Cardiology service at Hamad Medical Corporation, Doha, Qatar, which provides the main inpatient and outpatient tertiary care for the whole country and for the residents in Qatar (nationals and expatriates). More than $95 \%$ of cardiac patients are treated in this hospital making it an ideal center for populationbased studies. The Cardiology Database is maintained electronically from January 1991, and data up to December 2010 was used for present study. The data forms were filled by the Cardiologists at the time of patient discharge from the hospital according to predefined criteria for each data point. These records are coded, registered, and entered into a computer by a data entry operator and are randomly checked by the cardiology department [15]. The 20-yearsperiod was divided into 2 inclusive 10-year periods, (19912000 and 2001-2010). Information on management variables including cardiac medications, coronary reperfusion therapy [thrombolytic therapy, percutaneous coronary intervention (PCI), or coronary artery bypass grafting (CABG)], and all inhospital clinical complications and mortality was collected. Patients with incomplete data were excluded. The primary outcome of this analysis was all-cause in-hospital mortality while secondary outcomes included rates of in-hospital complications, such as resuscitated cardiac arrest, congestive heart failure (CHF), cardiogenic shock, and cerebrovascular accident (CVA). Ethical approval was obtained from MRC Research Committee, for the analysis and publication of the study.

\section{Definitions}

Initial MI was defined as AMI in a patient who denied pervious history of MI and the medical record did not show an evidence of previous MI.

3.1. Traditional Risk Factors. Diabetes mellitus (DM), hypertension, and dyslipidemia were identified when patients were known to have the given risk factor(s) prior to the index admission and/or were already on treatment for that condition. The presence of DM was determined by the documentation or diagnosis of DM that had been treated with medications or insulin. The presence of hypertension was determined by any documentation in the medical record of hypertension and/or if the patient was already on treatment by a physician. The presence of dyslipidemia was determined by the demonstration of a fasting cholesterol $>5.2 \mathrm{mmol} / \mathrm{L}$ in the patient's medical record and/or history of treatment of dyslipidemia.

3.2. Smoking History. Patients were defined as smoking any form of tobacco and divided into nonsmokers, current cigarette smokers, or past smokers (defined as more than 6month abstinence). Chronic renal impairment was defined as serum creatinine that is $>1.5$ times the upper normal range. Congestive heart failure $(\mathrm{CHF})$ was defined using the Framingham criteria. Minor criteria were acceptable only if they could not be attributed to any other medical condition (such as chronic lung disease, cirrhosis, ascites, or the nephrotic syndrome) [16]. Family history of premature CAD was defined as any direct blood relatives (parents, siblings, and children) who have had any of the following at 55 years or younger: angina, MI, or sudden cardiac death without obvious cause.

3.3. Statistical Analysis. Data were presented in the form of frequency and percentages for categorical variables and mean \pm standard deviation (SD) for interval variables. Baseline demographic characteristics, past medical history, clinical presentation, medical therapy, cardiac procedures, and in-hospital clinical outcomes of initial acute myocardial infarction (AMI) were analyzed across two inclusive tenyear periods from 1991-2000 to 2001-2010. Statistical analyses were performed using student $t$-tests or Wilcoxon Rank sum tests for interval variables between the two groups wherever applicable. Pearson chi-square $\left(\chi^{2}\right)$ tests were applied for categorical variables. Trends in cardiac medications with $\beta$ blockers, antiplatelets, and ACE inhibitors within 24 hours after presentation and at discharge were assessed. Also, trends in in-hospital mortality according to gender, age group, and type of the initial AMI were presented for every fiveyear period. Variables influencing in-hospital mortality (age, sex, risk factors, admission medications, and procedures) were assessed with multiple logistic regression analysis (enter method). Adjusted odds ratios (OR), 95\% CI, and $P$ values were reported for significant predictors for all and each group separately. All $P$ values were the results of 2-tailed tests and values $<0.05$ were considered statistically significant. Statistical Package for Social Sciences (SPSS) version 19.0 has been used for the analysis.

\section{Results}

4.1. Study Population. Between 1991 and the end of 2010, a total of 41,438 patients were hospitalized with acute cardiac diseases; of these, 10,915 (26.3\%) consecutive patients fitted the definition of initial AMI. The 20 -year study period was divided into 2 inclusive 10 -year periods. The characteristics of AMI patients across the study periods are shown in Table 1.

4.1.1. Trends in Patient Characteristics. Over the time periods studied, theoverall number of initial AMI hospitalization from total hospitalization increased from 3,740 (34\%) in 1991-2000 to 7,175 (66\%) in 2001-2010.

(i) Trends in Age, Gender, Ethnicity, and Initial AMI. Overall, the mean age of the study populations increased from $51 \pm 12$ to $54 \pm 12$ years $(P$ for trend $<0.001$ ). There was a significant decline in the rate of admission for younger patient age group ( $\leq 50$ years) from $53 \%$ to $43 \%$ but the proportion of elderly patients ( $>70$ years) increased from $6.0 \%$ to $9.0 \%$ (all $P$ for trend $<0.001)$. The proportion of South Asian (SA) to other 
TABle 1: Patients characteristics according to study period (1991-2010).

\begin{tabular}{|c|c|c|c|}
\hline Variables (\%) & $1991-2000$ & $2001-2010$ & $P$-value \\
\hline Number (\%) & $3740(34)$ & $7175(66)$ & 0.001 \\
\hline Age in year $($ mean $\pm S D)$ & $51 \pm 12$ & $54 \pm 12$ & 0.001 \\
\hline \multicolumn{4}{|l|}{ Age groups, years } \\
\hline$\leq 50$ & $1998(53)$ & $3074(43)$ & \multirow{3}{*}{0.001 For al } \\
\hline $51-70$ & $1510(40)$ & $3429(48)$ & \\
\hline$>70$ & $232(6)$ & $668(9)$ & \\
\hline Male gender & $3316(89)$ & $6294(88)$ & 0.21 \\
\hline \multicolumn{4}{|l|}{ Ethnicity } \\
\hline South Asians & $1828(49)$ & $3474(48)$ & \\
\hline Middle East Arabs & $1497(40)$ & $2642(37)$ & \\
\hline Others & $415(11.1)$ & $1059(14.8)$ & 0.001 \\
\hline \multicolumn{4}{|l|}{ Cardiovascular risk factors (\%) } \\
\hline Hypertension & $891(23.8)$ & $2834(39.5)$ & 0.001 \\
\hline Diabetes mellitus & $1169(31.3)$ & $2967(41.4)$ & 0.001 \\
\hline Current Smoking & $1086(29)$ & $2999(42)$ & 0.001 \\
\hline Dyslipidemia & $959(26)$ & $1276(18)$ & 0.001 \\
\hline Family history of CAD & $75(2)$ & $164(2.3)$ & 0.34 \\
\hline Body mass index $\left(\mathrm{Kg} / \mathrm{m}^{2}\right)($ mean $\pm \mathrm{SD})$ & $25 \pm 4$ & $27 \pm 6$ & 0.001 \\
\hline Obesity & $61(1.6)$ & $288(4)$ & 0.001 \\
\hline Chronic renal impairment & $42(1.1)$ & $241(3.4)$ & 0.001 \\
\hline Total cholesterol $(\mathrm{mmol} / \mathrm{L})($ mean $\pm \mathrm{SD})$ & $5.4 \pm 1.2$ & $5 \pm 1.3$ & 0.001 \\
\hline High-density lipoprotein cholesterol $(\mathrm{mmol} / \mathrm{L})($ mean $\pm \mathrm{SD})$ & $1.03 \pm 0.23$ & $1.02 \pm 0.31$ & 0.73 \\
\hline Serum triglyceride $(\mathrm{mmol} / \mathrm{L})($ mean $\pm \mathrm{SD})$ & $2.04 \pm 1.2$ & $1.9 \pm 1.16$ & 0.001 \\
\hline $\mathrm{CK}-\mathrm{MB}(\mathrm{u} / \mathrm{L})($ mean $\pm \mathrm{SD})$ & $380 \pm 1091$ & $190 \pm 570$ & 0.001 \\
\hline
\end{tabular}

CAD: coronary artery disease.

ethnicities and the ratio of men to women ratio did not change significantly. Nearly $50 \%$ of the study population was from SA and men accounted for the majority (88\%).

(ii) Trends of the Cardiovascular Risk Factors. With respect to cardiovascular risk factors, the rates of obesity, current smoking, hypertension (HTN), diabetes mellitus (DM), and chronic renal impairment increased significantly (all $P$ for trend $<0.001)$. Also, the body mass index (BMI) increased from $25 \pm 4$ to $27 \pm 6$ (mean \pm SD) (all $P$ for trend $<0.001$ ). However, family history of CAD did not change $(P<0.34)$, while dyslipidemia decreased over time from $26 \%$ to $18 \%$ ( $P$ for trend $<0.001)$. Although the total serum cholesterol and triglyceride (TG) levels decreased from $5.4 \pm 12$ to $5.0 \pm 1.3$ and from $2.04 \pm 1.2$ to $1.9 \pm 1.16$, respectively, ( $P$ for trend $<0.001)$ the mean HDL-C level did not change over the study period $(1.03 \pm 0.23$ to $1.02 \pm 0.31, P$ for trend $<0.73)$.

\subsubsection{Trends in Management}

Trends in the Use of Medical Therapies, Coronary Reperfusion, and Revascularization Procedures. In the entire study population, a significant increase in the use of certain CV medications during hospitalization was observed over the span of 20 years including marked increases in the use of
ACE inhibitors (from $12 \%$ to $36 \%$ ) and $\beta$-blockers (from 38\% to $56 \%$ ). Less but significant increase was also noted in the use of antiplatelet drugs (from $84 \%$ to $95 \%$ ) and in the use of heparins (unfractionated and LMWH) (from 56\% to 59\%) (all $P$ for trend $<0.001$ ) (Table 2) (Figure 1).

During the last two decades, thrombolytic therapy was used as a primary reperfusion therapy; however there was a substantial change in the proportion of patients who were treated with PCI. The rate of thrombolytic therapy administration declined from $71 \%$ to $65 \%$ while the rate of PCI increased from $2.5 \%$ to $14.6 \%(P<0.001)$. Finally, no significant trends were found forthe rate ofCABG ( $P$ for trend $<0.99$ ) (Figure 2).

(i) Medication at Discharge. At discharge, there was a significant increase in the use of evidence based CV medications including ACE inhibitors (from $12 \%$ to $36 \%$ ), $\beta$-blockers (from $38 \%$ to $56 \%$ ), and antiplatelet drugs (from $89 \%$ to $97 \%$ ), $P$ for trend $<0.001$ for all.

Trends in Hospital Length of Stay and Outcomes (Table 2). Although there was no significant change between the 2 decades regarding the length of stay in the coronary care unit $(3 \pm 1.7$ versus $3 \pm 1.6$ days $(P$ for trend $<0.40)$, the total hospital stay was reduced by $28 \%$, from $6.4 \pm 3$ days to $4.6 \pm 3$ days $(P<0.001)$. 
TABLE 2: Management and in-hospital outcomes according to study period (1991-2010).

\begin{tabular}{|c|c|c|c|}
\hline Variables (\%) & 1991-2000 & 2001-2010 & $\begin{array}{l}P \text {-value } \\
\text { for trend }\end{array}$ \\
\hline \multicolumn{4}{|l|}{$\begin{array}{l}\text { Medication during } 1 \text { st } 24 \mathrm{~h} \\
\text { of admission }\end{array}$} \\
\hline Thrombolytic & $1820(71)$ & $2516(65)$ & 0.001 \\
\hline Antiplatelet drugs & $3122(84)$ & $6822(95)$ & 0.001 \\
\hline Heparin & $2105(56)$ & $4249(59)$ & 0.003 \\
\hline$\beta$-blockers & $1415(38)$ & $4005(56)$ & 0.001 \\
\hline ACE inhibitors/ARB & $452(12)$ & $2579(36)$ & 0.001 \\
\hline Coronary angiography & $1161(31)$ & $1309(18)$ & 0.001 \\
\hline PCI & $95(2.5)$ & $1051(14.6)$ & 0.001 \\
\hline CABG & $73(2)$ & $140(2)$ & 0.99 \\
\hline \multicolumn{4}{|l|}{ In-hospital outcomes } \\
\hline Death & $329(8.8)$ & $385(5.4)$ & 0.001 \\
\hline Cerebrovascular accident & $39(1)$ & $11(0.2)$ & 0.001 \\
\hline Cardiogenic shock & $138(3.7)$ & $207(2.9)$ & 0.02 \\
\hline Cardiac arrest & $266(7.1)$ & $363(5.1)$ & 0.001 \\
\hline Congestive heart failure & $210(5.6)$ & $252(3.5)$ & 0.001 \\
\hline \multicolumn{4}{|l|}{ Medication at discharge } \\
\hline Antiplatelet agent & $3318(88.7)$ & $6931(96.6)$ & 0.001 \\
\hline$\beta$-blockers & $1415(37.8)$ & $4005(55.8)$ & 0.001 \\
\hline ACE inhibitors/ARB & $452(12.1)$ & $2579(35.9)$ & 0.001 \\
\hline \multicolumn{4}{|l|}{ Final discharge diagnosis } \\
\hline ST-elevation MI & $2547(68)$ & $3859(54)$ & \\
\hline Non-ST-elevation MI & $1193(32)$ & $3316(46)$ & 0.001 \\
\hline \multicolumn{4}{|l|}{ Hospital days (mean \pm SD) } \\
\hline Coronary care units stay & $3 \pm 1.7$ & $3 \pm 1.6$ & 0.40 \\
\hline Total hospital stay & $6.4 \pm 3$ & $4.6 \pm 3$ & 0.001 \\
\hline
\end{tabular}

$\mathrm{ACE}$ inhibitors/ARB: angiotensin converting enzyme inhibitors/angiotensin receptor blocker; CABG: coronary artery bypass grafting; PCI: percutaneous coronary intervention; $\mathrm{MI}$ : myocardial infarction.

During the study period, the overall in-hospital mortality had substantially decreased from $8.8 \%$ (in 1991-2000) to $5.4 \%$ (in 2001-2010), representing a $38.6 \%$ relative reduction. This was observed in all age groups and in both genders. However, female gender and the elderly (>70 years) were associated with higher mortality than their counterparts, males and younger patients ( $<70$ years), respectively. Also, the overall rates of in-hospital complications declined significantly, including cardiac arrest, CHF, cardiogenic shock, and CVA (all $P$ for trend $<0.001$ ).

4.2. Multivariate Logistic Regression Analysis (Table 3). We used logistic regression analysis to assess the mortality among patients hospitalized for initial AMI with adjustment for baseline variables.

The main predictors of in-hospital mortality included age (>70 years) (adjusted OR: 3.60, 95\% CI: 2.74-4.63, $P<$ 0.001 ), DM (adjusted OR: 1.8, 95\% CI: 1.81-2.15, $P<0.001$ ), and female gender (adjusted OR: 1.70, 95\% CI: 1.39-2.13,

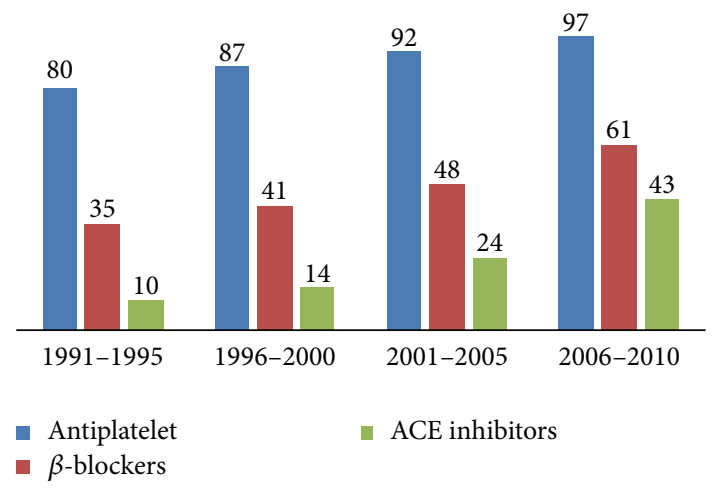

FIgURE 1: Trends in hospital medications (\%) over 2 decades.

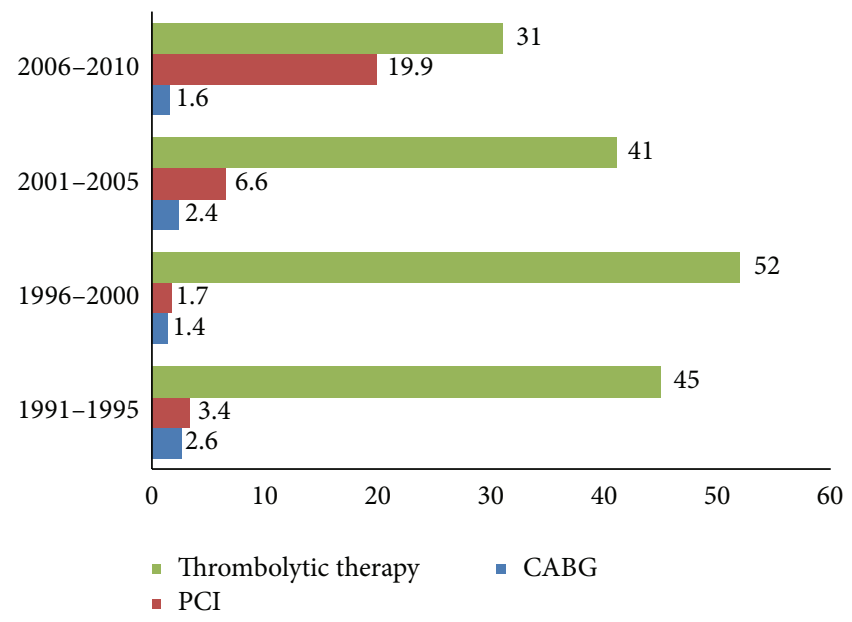

FIGURE 2: Trends in coronary reperfusion and revascularization procedures (\%) over 2 decades.

$P<0.001)$. Moreover, hospital therapies were associated with lower in-hospital mortality: antiplatelet drugs (adjusted OR: $0.20 ; 95 \%$ CI: $0.16-0.26$ ); $\beta$-blockers (adjusted OR: 0.28 ; 95\% CI: 0.23-0.34); ACE inhibitors (adjusted OR: 0.37; 95\% CI: $0.30-0.48$ ); and reperfusion therapy (adjusted OR: 0.66; 95\% CI: 0.47-0.98). The use of antiplatelet drugs, $\beta$ blockers, ACEI, and PCI was associated with a reduction in the in-hospital mortality rate by $80 \%, 72 \%, 63 \%$, and $34 \%$, respectively (Table 3 ).

The age-adjusted in-hospital mortality rate was higher in females compared with their counterpart males in all age groups. The difference in mortality between genders after initial AMI decreased with age (relative risk ranging from 4.0 (95\% CI: $2.56-6.25)$ at $\leq 50$ years to 2.27 (95\% CI: $1.79-2.94$ ) at $51-70$ years and 1.46 (95\% CI: $1.04-2.06)$ at $>70$ years).

\section{Discussion}

Our results provide several important insights into the population trends associated with initial AMI. (1) CAD risk factors control is still insufficient, which could largely account for the high burden and rate of AMI admissions. (2) Treatment with evidence based therapies increased over time and probably 
TABLE 3: Multivariate regression analysis for predictors of inhospital mortality.

\begin{tabular}{lccc}
\hline Variables & Adjusted OR & $95 \%$ CI & $P$-value \\
\hline Patients characteristics & & & \\
$\quad \leq 50$ yrs & 1 & - & - \\
$51-70$ yrs & 1.52 & $1.22-1.82$ & 0.001 \\
Age $>70$ yrs & 3.60 & $2.72-4.56$ & 0.001 \\
Female gender & 1.70 & $1.42-2.16$ & 0.001 \\
Diabetes mellitus & 1.78 & $1.51-2.15$ & 0.001 \\
Hypertension & 0.92 & $0.80-1.15$ & 0.38 \\
Current smoking & 0.83 & $0.63-0.96$ & 0.08 \\
$\quad$ Obesity & 0.85 & $0.57-1.46$ & 0.60 \\
Medication during & & & \\
admission & & & \\
(1st 24 hrs therapy) & & & \\
$\quad \beta$-blockers & 0.28 & $0.23-0.34$ & 0.001 \\
Antiplatelet drugs & 0.20 & $0.16-0.26$ & 0.001 \\
ACE/ARBs & 0.37 & $0.30-0.48$ & 0.001 \\
Heparin & 1.43 & $1.12-1.65$ & 0.001 \\
Thrombolytic & 0.83 & $0.70-1.02$ & 0.06 \\
Revascularization & & & \\
procedures & & & \\
PCI & 0.66 & $0.47-0.98$ & 0.03 \\
CABG & 0.45 & $0.25-0.90$ & 0.02 \\
\hline Ad & & &
\end{tabular}

Adjusted OR: adjusted odd ratio; 95\% CI: 95\% confidence interval.

played a major role in shorter hospital stay and significant improvement in hospital outcomes of both mortality and morbidity. (3) Despite these encouraging trends, there is an opportunity for better control of risk factors and more optimal use of evidence based therapies.

5.1. Baseline Characteristics. From decade to decade, we noticed increased mean age among patients hospitalized with initial AMI which may suggest improvement in primary prevention of CAD throughout the last decade. The overall age in the entire study period was 52 years, which is significantly younger by almost 10 years when compared with reports from the developed countries [17, 18]. This finding may be contributed to South Asians by a higher proportion,, a population known to be prone to develop CAD at a younger age and increased CV risk factor burden [1922]. The latter may have also contributed to increased rate of initial AMI [23]. An increased proportion of CV risk factors in patients with AMI suggests further opportunities for aggressive screening and risk factors modification and reinforces the importance of preventive measures by lifestyle advice and drugs.

Previous studies have suggested that the incidence of $\mathrm{CAD}$ and associated mortality has declined in many countries [22, 24-27]. Data from MIYAGI-AMI registry study demonstrated that in the last two decades there was a steady trend of increasing incidence of AMI [23].
In the present study, we report an increased rate of AMI hospitalization from $34 \%$ to $66 \%$ in the last two decades. Explaining the increased rate in initial AMI hospitalization in our study is complex. Part of this increase might be due to change in criteria defining AMI [28]. The increased penetration and utilization of troponin as biomarker in Qatar from 1999 onwards would be expected to lead to an increase in AMI hospitalizations. Our data are also in agreement with prior studies in which the rate of AMI was predominantly of the male gender $[29,30]$.

We observed a significant improvement in in-hospital mortality and morbidity in all age groups and in both genders. The current study reported $6.5 \%$ reduction in overall inhospital mortality rate which is comparable with other European registries (7\% in the Euro heart survey and GRACE) $[31,32]$.

In an attempt to understand the reasons behind this improvement in hospital outcomes, we carried out further analysis taking into account the different therapies that were provided. From 2001 onward, we demonstrated a significant increase in the utilization of ACE inhibitors and $\beta$-blockers. Smaller increases were noted in the use of antiplatelet and subtle increase in the use of heparins during the initial 24 hours after admission. Multivariate adjustment suggests that most of the decrease in mortality is probably related to improved quality of treatment according to the guidelines and the revascularization interventions [11,33].

Previous trials [34-40] have suggested a significant role of some drugs in lowering early CV mortality when used in the acute phase of AMI. In particular, GISSI- 3 and ISIS- 4 trials demonstrated a marginal but statistically significant mortality reduction when ACE inhibitors were started early and persisted up to one year follow up. The ACC/AHA guidelines recommend the administration of ACE inhibitors within the initial 24 hours of STEMI in the absence of hypotension or known contraindications (class I, level of evidence A) [3]. Several large trials including ISIS-1 MIAMI, TIMI-IIb, and GUSTO-I recommended $\beta$-blockers early in the setting of AMI. Our findings support the recommendation that both $\mathrm{BBs}$ and ACE inhibitors were major contributors to the decreased in-hospital mortality, which is consistent with the published trials [37-42].

Despite this improvement in practice, the overall rate of utilization of some of these drugs is still below the current standards when compared to other larger multinational registries [4], and further efforts are therefore needed to optimize their use. Moreover, the hospital stay is expected to decrease further with a full implementation of the recent primary PCI program in Qatar [43].

Another finding which is consistent with AMIS plus registry [44] was the increase in the proportion of acute MI patients treated by PCI and a reduction in the use of thrombolytic therapy, in our study. However, the increase in PCI procedures observed was considerably low which is in agreement with a recent study in 6 Middle-Eastern countries [45]. Such Improvements in management including increased use of evidence-based therapies may have contributed to the decline in hospital stay shown in this study. Throughout the study period, the rate of CABG remained 
stable at around $2 \%$, a finding consistent with a recent report in the other countries like USA [46].

5.2. Study Strengths and Limitations. This study of trends over 20-year period for the initial AMI hospitalizations must be viewed in the context of a number of changes in the clinical practice in the last 2 decades. The inclusion of all patients hospitalized with initial AMI provides a unique opportunity to closely examine the trends in the therapeutic management of an unselected population of all ages. Each data collection period occurred over 10 years and this approach ensures a large enough sample size and represents strength of this study. To the best of our knowledge this is the first study from the Middle East to address the changes in the management and mortality in patients hospitalized with initial acute MI. It is conducted in a large population and over a long time period. Our study is constrained by limitations which are inherent in all studies of historical, observational design. Inaccuracies in the diagnosis and coding of AMI in routine data are well recognized. This could lead to missing of some data or measurement errors. However, the same methodology was used throughout the study period. Our study focused on in-hospital outcomes, but long-term outcomes were not available.

Finally, in spite of these limitations, the findings of this study are interesting as it compares a cohort of unselected patients hospitalized with initial AMI representing the changes in hospital course, treatment strategies, and patient outcome over 2 decades.

\section{Conclusion}

Over the last two decades, there is a significant improvement in the in-hospital outcomes in patients hospitalized with initial AMI. This parallels a significant increase in the use of evidence based therapies. However, there is a growing burden of risk factors. Efforts are therefore needed to further optimize the management and reduce the burden of risk factors in the Middle East.

\section{Conflict of Interests}

The authors have no conflict of interests and no financial issues to disclose.

\section{Acknowledgment}

The authors thank all the cardiology staff at HMC for their efforts to collect and enter the data over the whole study period.

\section{References}

[1] WHO, World Health Statistics 2008, World Health Organization, Geneva, Switzerland, 2008, http://www.who.int/whosis/ whostat/EN_WHS08_Full.pdf.

[2] E. Braunwald, E. M. Antman, J. W. Beasley et al., "ACC/AHA 2002 guideline update for the management of patients with unstable angina and non-ST-segment elevation myocardial infarction-summary article: a report of the American College of Cardiology/American Heart Association Task Force on Practice Guidelines," Journal of the American College of Cardiology, vol. 40, no. 7, pp. 1366-1374, 2002.

[3] E. M. Antman, D. T. Anbe, P. W. Armstrong et al., "American College of Cardiology, American Heart Association Task Force on Practice Guidelines, Canadian Cardiovascular Society. ACC/AHA guidelines for the management of patients with ST-elevation myocardial infarction: a report of the American College of Cardiology/American Heart Association Task Force on Practice Guidelines (Committee to Revise the 1999 Guidelines for the Management of Patients With Acute Myocardial Infarction)," Circulation, vol. 110, no. 9, pp. e82-e292, 2004.

[4] T. J. Ryan, E. M. Antman, N. H. Brooks et al., "1999 update: ACC/AHA guidelines for the management of patients with acute myocardial infarction: a report of the American College of Cardiology/American Heart Association Task Force on Practice Guidelines (Committee on Management of Acute Myocardial Infarction)," Journal of the American College of Cardiology, vol. 34, no. 3, pp. 890-911, 1999.

[5] S. Yusuf, P. Sleight, J. Pogue, J. Bosch, R. Davies, and G. Dagenais, "Heart outcomes prevention evaluation study investigators. Effects of an angiotensin-convertingenzyme inhibitor, ramipril, on cardiovascular events in high risk patients," The New England Journal of Medicine, vol. 342, no. 3, pp. 145-153, 2000.

[6] Instituto Nacional de Estadística, "Defunciones según la causa de muerte 2006," http://www.ine.es.

[7] C. J. L. Murray and A. D. Lopez, "Alternative projections of mortality and disability by cause 1990-2020: Global Burden of Disease Study," The Lancet, vol. 349, no. 9064, pp. 1498-1504, 1997.

[8] H. Tunstall-Pedoe, K. Kuulasmaa, M. Mähönen, H. Tolonen, E. Ruokokoski, and P. Amouyel, "Contribution of trends in survival and coronary-event rates to changes in coronary heart disease mortality: 10-year results from 37 WHO MONICA Project populations," The Lancet, vol. 353, no. 9164, pp. 15471557, 1999.

[9] M. Gil, H. Martí, R. Elosúa et al., "Analysis of trends in myocardial infarction case-fatality, incidence and mortality rates in Girona, Spain, 1990-1999," Revista Espanola de Cardiologia, vol. 60, no. 4, pp. 349-356, 2007.

[10] F. van de Werf, D. Ardissino, A. Betriu et al., "Management of acute myocardial infarction in patients presenting with STsegment elevation," European Heart Journal, vol. 24, no. 1, pp. 28-66, 2003.

[11] F. G. Kushner, M. Hand, S. C. Smith Jr. et al., "2009 Focused updates: ACC/AHA guidelines for the management of patients with st-elevation myocardial infarction (updating the 2004 guideline and 2007 focused update) and ACC, (AHA/SCAI guidelines on percutaneous coronary intervention (updating the 2005 guideline and 2007 focused update)," Journal of the American College of Cardiology, vol. 54, pp. 2205-2241, 2009.

[12] K. Kalla, G. Christ, R. Karnik et al., "Implementation of guidelines improves the standard of care: the Viennese registry on reperfusion strategies in ST-elevation myocardial infarction (Vienna STEMI Registry)," Circulation, vol. 113, no. 20, pp. 2398-2405, 2006.

[13] E. S. Ford, U. A. Ajani, J. B. Croft et al., "Explaining the decrease in U.S. deaths from coronary disease, 1980-2000," The New England Journal of Medicine, vol. 356, no. 23, pp. 2388-2398, 2007. 
[14] S. L. Hardoon, P. H. Whincup, L. T. Lennon, S. G. Wannamethee, S. Capewell, and R. W. M. Richard W. Morris, "How much of the recent decline in the incidence of myocardial infarction in british men can be explained by changes in cardiovascular risk factors? evidence from a prospective populationbased study," Circulation, vol. 117, no. 5, pp. 598-604, 2008.

[15] J. Al Suwaidi, A. Al-Qahtani, N. Asaad, A. W. Al-Mulla, R. Singh, and H. A. Albinali, "Comparison of women versus men hospitalized with heart failure (from a 20-year registry in a Middle-Eastern country 1991-2010)," American Journal of Cardiology, vol. 109, no. 3, pp. 395-400, 2012.

[16] J. Al Suwaidi, A. Bener, H. A. Hajar, and M. T. Numan, "Does hospitalization for congestive heart failure occur more frequently in Ramadan: apopulation-based study (1991-2001)," International Journal of Cardiology, vol. 96, no. 2, pp. 217-221, 2004.

[17] F. A. Masoudi, J. M. Foody, E. P. Havranek et al., "Trends in acute myocardial infarction in 4 US States between 1992 and 2001: clinical characteristics, quality of care, and outcomes," Circulation, vol. 114, no. 25, pp. 2806-2814, 2006.

[18] V. S. Steiger, J.-J. Goy, J.-C. Stauffer et al., "Significant decrease in in-hospital mortality and major adverse cardiac events in Swiss STEMI patients between 2000 and December 2007," Swiss Medical Weekly, vol. 139, no. 31-32, pp. 453-457, 2009.

[19] M. Gupta, A. V. Doobay, N. Singh et al., "Risk factors, hospital management and outcomes after acute myocardial infarction in South Asian Canadians and matched control subjects," Canadian Medical Association Journal, vol. 166, no. 6, pp. 717722, 2002.

[20] P. S. Yusuf, S. Hawken, S. Ônpuu et al., "Effect of potentially modifiable risk factors associated with myocardial infarction in 52 countries (the INTERHEART study): case-control study," The Lancet, vol. 364, no. 9438, pp. 937-952, 2004.

[21] U. N. Khot, M. B. Khot, C. T. Bajzer et al., "Prevalence of conventional risk factors in patients with coronary heart disease," Journal of the American Medical Association, vol. 290, no. 7, pp. 898-904, 2003.

[22] C. S. Fox, J. C. Evans, M. G. Larson, W. B. Kannel, and D. Levy, "Temporal trends in coronary heart disease mortality and sudden cardiac death from 1950 to 1999: the Framingham Heart Study," Circulation, vol. 110, no. 5, pp. 522-527, 2004.

[23] T. Takii, S. Yasuda, J. Takahashi et al., "Trends in acute myocardial infarction incidence and mortality over 30 years in Japan: report from the MIYAGI-AMI registry study," Circulation Journal, vol. 74, no. 1, pp. 93-100, 2010.

[24] N. I. Parikh, P. Gona, M. G. Larson et al., "Long-term trends in myocardial infarction incidence and case fatality in the national heart, lung, and blood institute's Framingham Heart Study," Circulation, vol. 119, no. 9, pp. 1203-1210, 2009.

[25] P. G. McGovern, D. R. Jacobs Jr., E. Shahar et al., “Trends in acute coronary heart disease mortality, morbidity, and medical care from 1985 through 1997: the Minnesota Heart Survey," Circulation, vol. 104, no. 1, pp. 19-24, 2001.

[26] V. L. Roger, S. J. Jacobsen, S. A. Weston et al., “Trends in the incidence and survival of patients with hospitalized myocardial infarction, Olmsted County, Minnesota, 1979 to 1994," Annals of Internal Medicine, vol. 136, no. 5, pp. 341-348, 2002.

[27] K. C. Floyd, J. Yarzebski, F. A. Spencer et al., "A 30-year perspective (1975-2005) into the changing landscape of patients hospitalized with initial acute myocardial infarction Worcester Heart Attack Study," Circulation: Cardiovascular Quality and Outcomes, vol. 2, no. 2, pp. 88-95, 2009.
[28] J. S. Alpert, K. Thygesen, E. Antman, and J. P. Bassand, "Myocardial infarction redefined-a consensus document of The Joint European Society of Cardiology/American College of Cardiology Committee for the redefinition of myocardial infarction," Journal of the American College of Cardiology, vol. 36, no. 3, pp. 959-969, 2001.

[29] A. A. Gehani, A. T. Al-Hinai, M. Zubaid et al., "Association of risk factors with acute myocardial infarction in Middle Eastern countries: the INTERHEART Middle East Study," European Journal of Preventive Cardiology, vol. 21, no. 4, pp. 400-410, 2014.

[30] B. K. Nallamothu, J. Young, H. S. Gurm, G. Pickens, and K. Safavi, "Recent trends in hospital utilization for acute myocardial infarction and coronary revascularization in the United States," American Journal of Cardiology, vol. 99, no. 6, pp. 749-753, 2007.

[31] D. Hasdai, S. Behar, L. Wallentin et al., "A prospective survey of the characteristics, treatments and outcomes of patients with acute coronary syndromes in Europe and the Mediterranean basin: the Euro Heart Survey of Acute Coronary Syndromes," European Heart Journal, vol. 23, no. 15, pp. 1190-1201, 2002.

[32] K. A. A. Fox, S. G. Goodman, W. Klein et al., "Management of acute coronary syndromes. Variations in practice and outcome: findings from the Global Registry of Acute Coronary Events (GRACE)," European Heart Journal, vol. 23, no. 15, pp. 1177-1189, 2002.

[33] P. Kolh and W. Wijns, "Joint ESC/EACTS guidelines on myocardial revascularization," Journal of Cardiovascular Medicine, vol. 12, no. 4, pp. 264-267, 2011.

[34] S. Yusuf, F. Zhao, S. R. Mehta, S. Chrolavicius, G. Tognoni, and K. K. Fox, "Effects of clopidogrel in addition to aspirin in patients with acute coronary syndromes without ST-segment elevation," The New England Journal of Medicine, vol. 345, no. 7, pp. 494-502, 2001.

[35] C. De Vita, P. F. Fazzini, E. Geraci et al., "GISSI-3: effects of lisinopril and transdermal glyceryl binitrate singly and together on 6-week mortality and ventricular function after acute myocardial infarction," The Lancet, vol. 343, no. 8906, pp. 1115-1122, 1994.

[36] R. Collins, R. Peto, M. Flather et al., "ISIS-4: a randomised factorial trial assessing early oral captopril, oral mononitrate, and intravenous magnesium sulphate in 58050 patients with suspected acute myocardial infarction," The Lancet, vol. 345, no. 8951, pp. 669-685, 1995.

[37] "Randomised trial of intravenous atenolol among 16027 cases of suspected acute myocardial infarction: ISIS-1. First International Study of Infarct Survival Collaborative Group," The Lancet, vol. 2, no. 8498, pp. 57-66, 1986.

[38] A. Hjalmarson, J. Herlitz, and S. Holmberg, "Metoprolol in acute myocardial infarction (MIAMI). A randomised placebocontrolled international trial," European Heart Journal, vol. 6, no. 3, pp. 199-226, 1985.

[39] R. Roberts, W. J. Rogers, H. S. Mueller et al., "Immediate versus deferred $\beta$-blockade following thrombolytic therapy in patients with acute myocardial infarction. Results of the thrombolysis in myocardial infarction (TIMI) II-B study," Circulation, vol. 83, no. 2, pp. 422-437, 1991.

[40] M. Pfisterer, J. L. Cox, C. B. Granger et al., "Atenolol use and clinical outcomes after thrombolysis for acute myocardial infarction: the GUSTO-I experience," Journal of the American College of Cardiology, vol. 32, no. 3, pp. 634-640, 1998.

[41] K. J. Harjai, G. W. Stone, J. Boura et al., "Effects of prior betablocker therapy on clinical outcomes after primary coronary 
angioplasty for acute myocardial infarction," American Journal of Cardiology, vol. 91, no. 6, pp. 655-660, 2003.

[42] K. F. Carruthers, O. H. Dabbous, M. D. Flather et al., "Contemporary management of acute coronary syndromes: does the practice match the evidence? The global registry of acute coronary events (GRACE)," Heart, vol. 91, no. 3, pp. 290-298, 2005.

[43] A. Gehani, J. Al Suwaidi, S. Arafa et al., "Primary coronary angioplasty for ST-elevation myocardial infarction: first Nationwide Program in Qatar," Global Cardiology Science and Practice, no. 1, pp. 23-29, 2012.

[44] A.-A. Fassa, P. Urban, D. Radovanovic et al., "Temporal trends in treatment of ST segment elevation myocardial infarction in Switzerland from 1997 to 2005," Revue Medicale Suisse, vol. 2, no. 67, pp. 1393-1398, 2006.

[45] P. Panduranga, K. Sulaiman, I. Al-Zakwani et al., "Utilization and determinants of in-hospital cardiac catheterization in patients with acute coronary syndrome from the Middle East," Angiology, vol. 61, no. 8, pp. 744-750, 2010.

[46] A. J. Epstein, D. Polsky, F. Yang, L. Yang, and P. W. Groeneveld, "Coronary revascularization trends in the united states, 20012008," Journal of the American Medical Association, vol. 305, no. 17, pp. 1769-1776, 2011. 


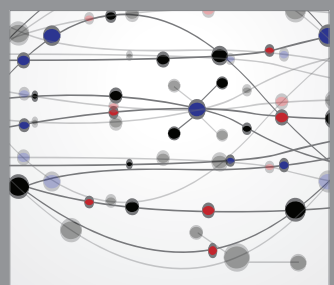

The Scientific World Journal
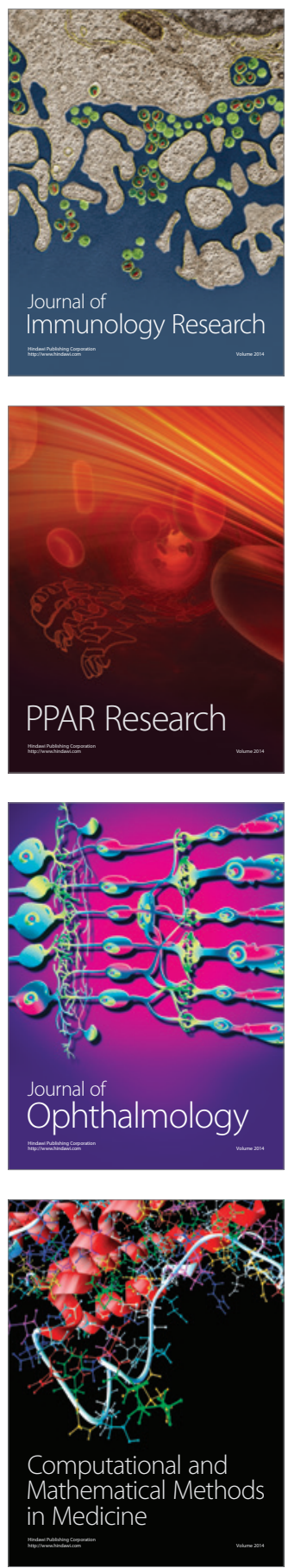

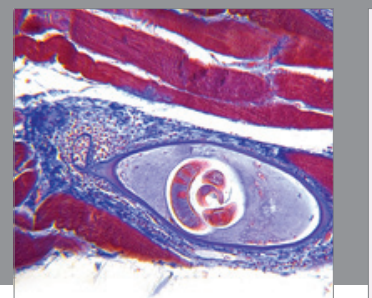

Gastroenterology

Research and Practice
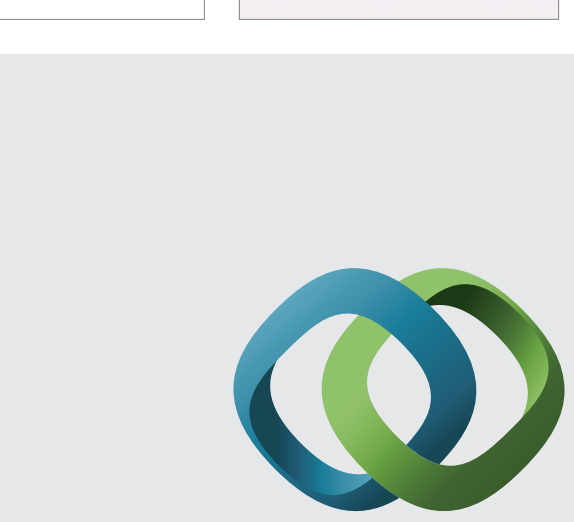

\section{Hindawi}

Submit your manuscripts at

http://www.hindawi.com
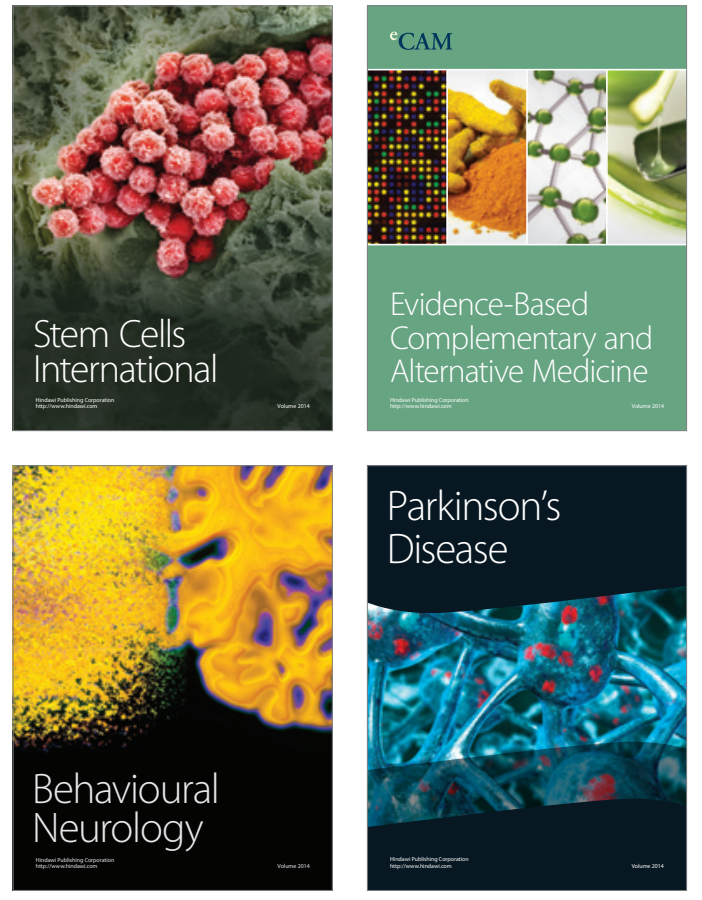
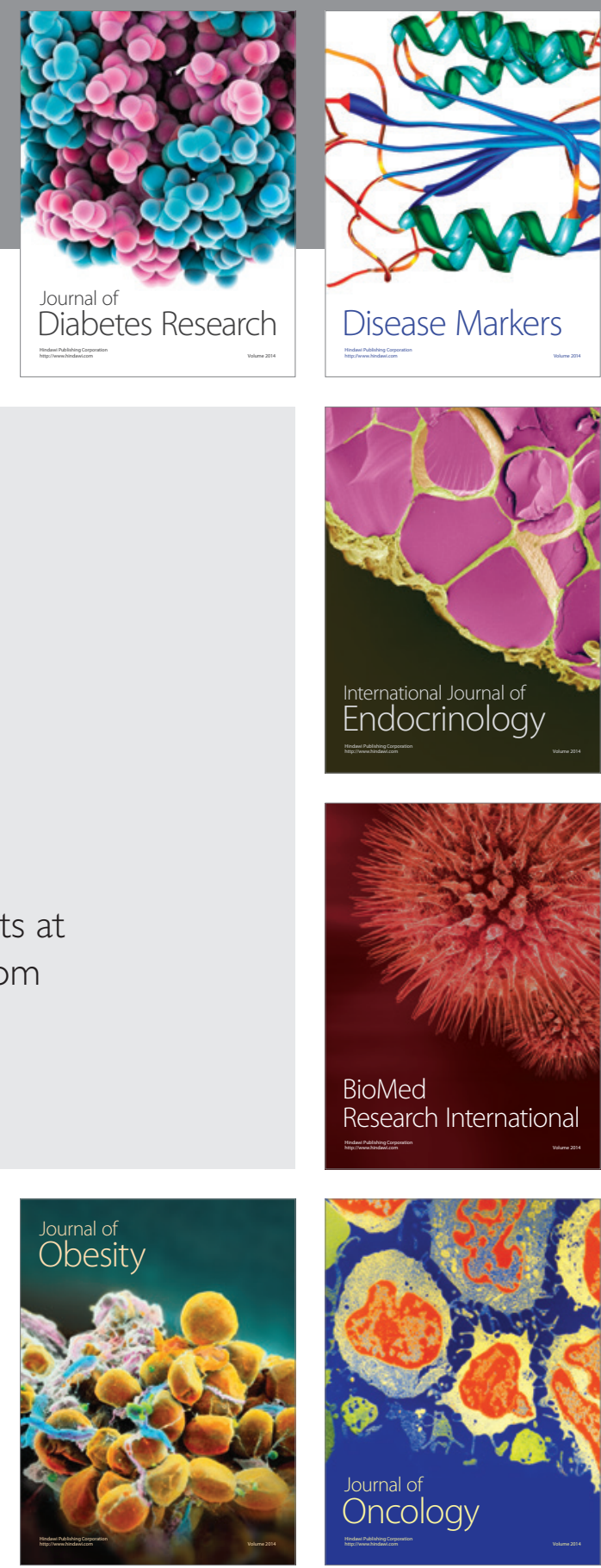

Disease Markers
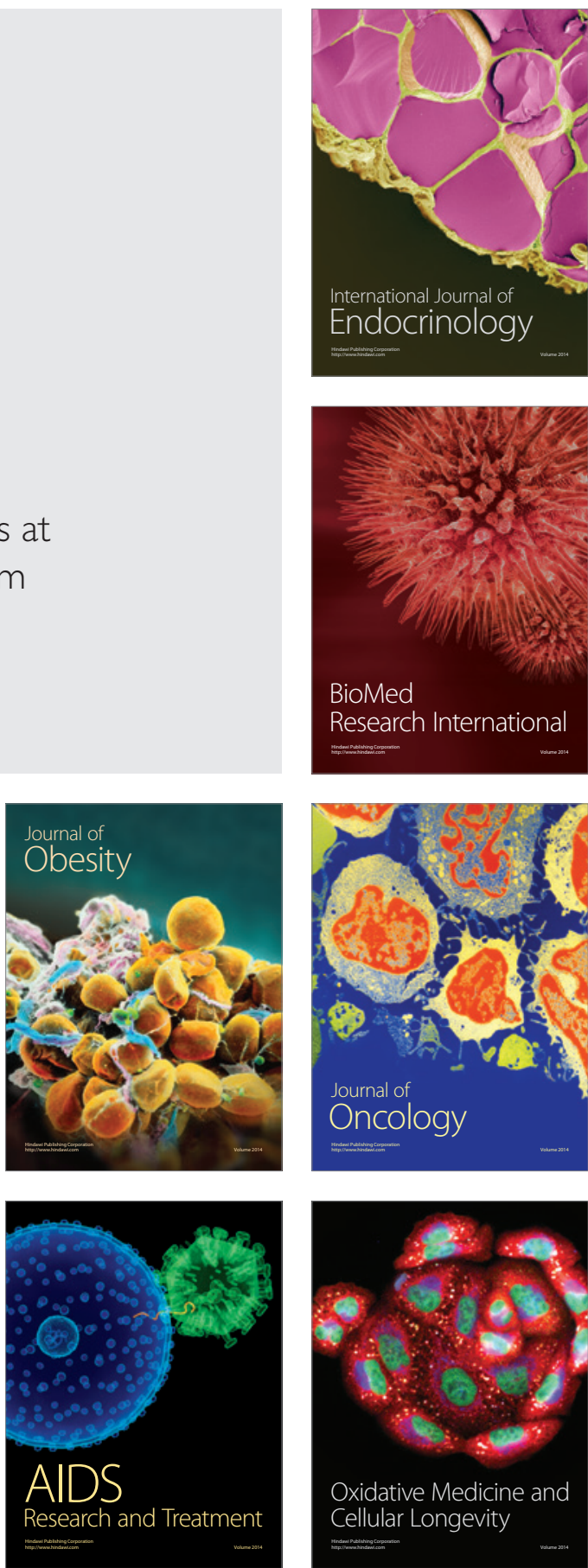